
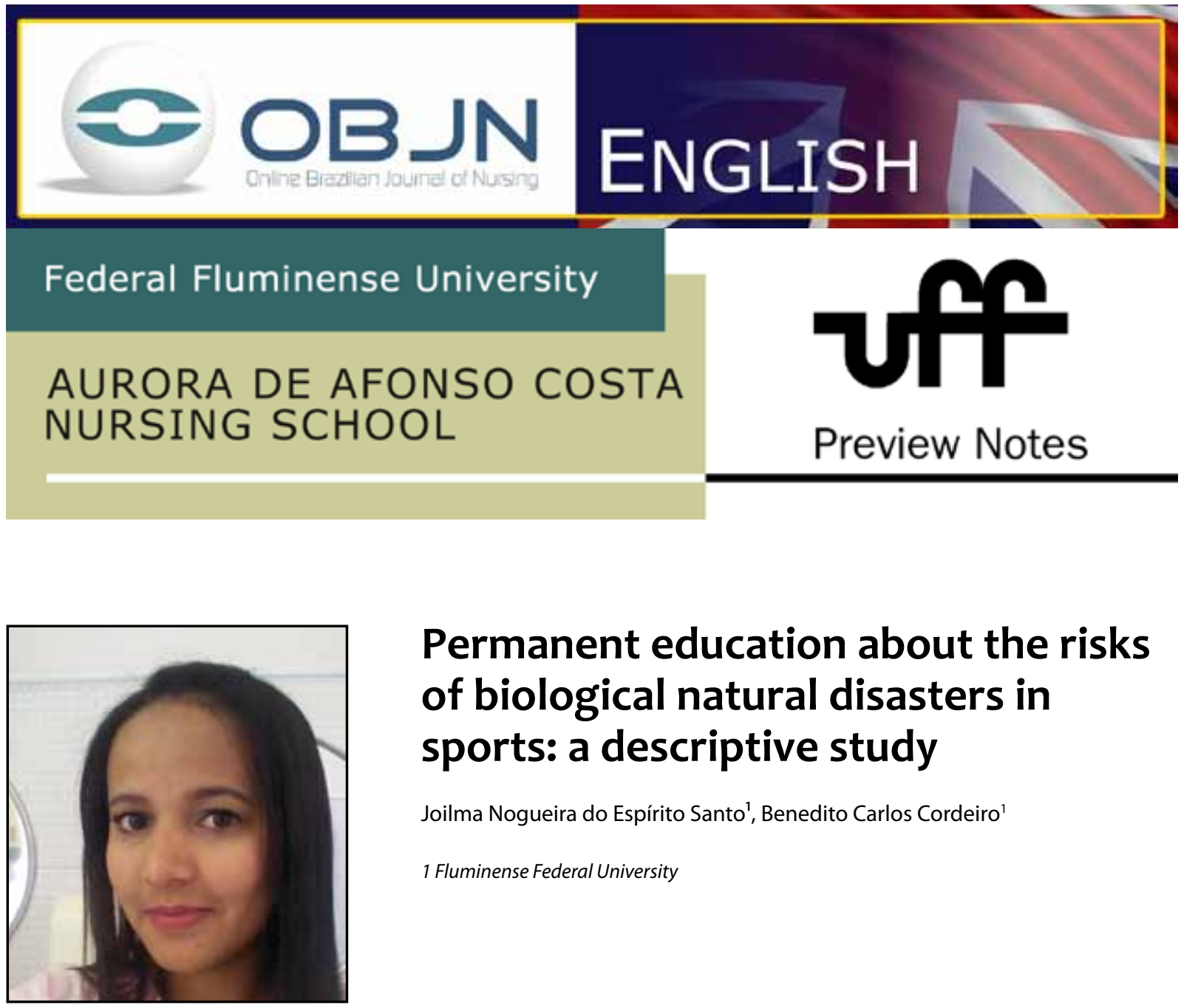

\title{
Permanent education about the risks of biological natural disasters in sports: a descriptive study
}

\author{
Joilma Nogueira do Espírito Santo', Benedito Carlos Cordeiro \\ 1 Fluminense Federal University
}

\section{ABSTRACT}

Aims: To demonstrate and to report on the views of Physical Education (PE) teachers of the Fluminense Federal Institute (IFF, in Portuguese) about biological natural disasters; to identify and to describe the risks of misfortune in sport trips; to implement, through distance learning, a permanent education in health (PEH) system regarding biological disasters for the PE teachers of IFF, based on the risks found in sport trips. Method: This is a descriptive, exploratory study, with a qualitative approach, using field research, in terms of which PE teachers will make up the target population. The data will be collected in October 2014 from a bibliographical research and from recorded semi-structured interviews. The content will be analyzed according to the ideas of Bardin. It is expected that the PEH proposal will allow these professionals to understand and prevent the issues dealt with in this paper.

Descriptors: Natural Disasters; Education, Continuing; Education in Disasters; Faculty. 


\section{PROBLEM SITUATION AND ITS SIGNIFICANCE}

There is a tendency in Brazilian society to believe that disasters are only generated when the weather is rainy or dry, or in periods of some other similar weather event. This erroneous perception has generated effects that, in many cities, there are no systematic response forces that can work on the existing countless threats and vulnerabilities ${ }^{(1)}$. Natural disasters are events caused by natural forces or phenomena, which can lead to damage to health, or even death. In addition, such events can cause environmental and material damage, the interruption of many public services, and social and economic unbalance. Biological natural disasters include epidemics and infections caused by insects and demand more attention, not only from the public sector, but also from the whole of Brazilian society ${ }^{(2)}$. It is necessary to develop educational action that develops awareness with regard to precautionary measures, so that everyone is ready to act in future events.

It is important to mention that prevention is the best solution, and it is through the introduction of educational measures that it will be possible to solve the issues before they start. Another need is the development of a permanent education in health (PEH) system that enables the perception and the prevention of these problems. The implementation of a permanent educational system would permit institutions to use it within a problematizing pedagogic context, with the intention of stimulating the reflection of the praxis and the construction of knowledge $\mathrm{e}^{(3)}$. Introducing a permanent education system inside a school environment would enable reflection over the need to adopt steps to increase the awareness of disaster risks, and therefore, reduce the effects of such events.

\section{GUIDING QUESTIONS}

What are the views of Physical Education (PE) teachers regarding biological natural disasters? How do they identify and describe the risks of such dangers in sport trips? How ought we to implement a permanent educational system with regard to biological disasters for PE teachers?

AIMS

General: to implement a PEH policy for PE teachers at the Fluminense Federal Institute (IFF, in Portuguese), aiming to contribute to the increased perception of risk and the prevention of biological natural disasters in sport trips. Specific: to demonstrate and to report the views of $P E$ teachers regarding biological natural disasters; to identify and to describe the risks found in sport trips; to implement, using distance learning, a permanent education system based on the risks found in sport trips.

\section{PREMISSES}

It is believed that this research will generate permanent education tools for PE teachers at the IFF, which will enable them to facilitate the spread of information regarding health practices inside the school. They can also support the building of a more appropriate instrument which will be wider, more diversified and resolute regarding the risks of biological natural disasters, in order to support the school better.

\section{METHOD}

This is a descriptive study, with exploratory characteristics and a qualitative approach, using 
field research, which will take place in a public federal school located in the city of Campos dos Goytacazes, Brazil. The target population will be the PE teachers, based on the criteria of inclusion and professional approval to participate in all steps of the research. In terms of exclusion, those teachers who are on medical leave or who have left the institution before the end of this research will not participate. The expected number of interviewees is around 20 teachers who are involved with students who travel in order to participate in championships and other sporting events.

The information will be collected during October 2014 in the form of a semi-structured interview which will be recorded, and through a bibliographic research using the Lilacs, Bdenf and Desastres databases, using the keywords Natural Disasters, Continuing Education, Education in Disasters, and Faculty. The content will be analyzed based on the teachings of Bardin. This project will follow Resolution 466/12 of the Brazilian National Health Council, which determines the directives and rules of research that involve human beings; it was approved by the Committee of Ethics in Research of Antônio Pedro Hospital in Aug. 08, 2014, under protocol \#755.453.

\section{REFERENCES}

1. Centro Universitário de Estudos e Pesquisas sobre Desastres. Universidade Federal de Santa Catarina. Capacitação Básica em Defesa Civil. 2011; [cited 2014 Feb 27]. Available from: http:// ceped.ufsc.br/sites/default/files/projetos/pr__2011.106_-_conteudo_completo_0.pdf

2. Ministério da Integração Nacional (Brasil); Secretaria Nacional de Defesa Civil. Instrução Normativa $\mathrm{n}^{\circ}$ 001, de 24 de agosto de 2012. Estabelece procedimentos e critérios para a decretação de situação de emergência ou estado de calamidade pública pelos Municípios, Estados e pelo Distrito Federal, e para o reconhecimento federal das situações de anormalidade decretadas pelos entes federativos e dá outras providências. Diário Oficial da União 30 ago 2012; Seção 1.

3. Godinho, JSL, Tavares, CMM. The permanent education in intensive care units: a review article. Online brazj nurs [Internet].2009 Aug [cited 2013 Aug 03]; 8 (2): [about 4 p.]. Available from: http:// www.objnursing.uff.br/index.php/nursing/article/view/j.16764285.2009.228. doi:http://dx.doi. org/10.5935/1676-4285.20092288

\section{Project Information}

Dissertation project of the Professional Master in Health Education: Interdisciplinary Professor Formation for the Brazilian Unified Health System.

Master student: Joilma Nogueira do Espírito Santo

Tutor: Benedito Carlos Cordeiro

All authors participated in the phases of this publication in one or more of the following steps, in According to the recommendations of the International Committee of Medical Journal Editors (ICMJE, 2013): (a) substantial involvement in the planning or preparation of the manuscript or in the collection, analysis or interpretation of data; (b) preparation of the manuscript or conducting critical revision of intellectual content; (c) approval of the versión submitted of this manuscript. All authors declare for the appropriate purposes that the responsibilities related to all aspects of the manuscript submitted to OBJN are yours. They ensure that issues related to the accuracy or integrity of any part of the article were properly investigated and resolved. Therefore, they exempt the OBJN of any participation whatsoever in any imbroglios concerning the content under consideration. All authors declare that they have no conflict of interest of financial or personal nature concerning this manuscript which may influence the writing and/or interpretation of the findings. This statement has been digitally signed by all authors as recommended by the ICMJE, whose model is available in http://www. objnursing.uff.br/normas/DUDE_eng_13-06-2013.pdf

Received: 09/02/2014

Revised: 09/23/2014

Approved: 09/23/2014 